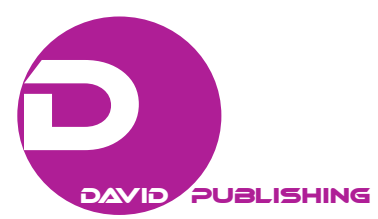

\title{
Cost Effectiveness Analyses Models in the Defence System in Republic Bulgaria
}

\author{
Venelin Krastev Terziev \\ University of Agribusiness and Regional Development, Plovdiv, Bulgaria \\ Sevdalina Ilieva Dimitrova \\ National Military University "Vasil Levski”, Veliko Tarnovo, Bulgaria
}

\begin{abstract}
The thesis resulting from the research on the "costs-effects" relation is the principle of economic efficiency of defence capabilities. At first glance, the arguments in this direction are well-known and popular in crisis situations of various nature, including the current financial and economic crisis in the country, and the question about the cost of public welfare-security and defence is debatable. This cost is manifested through the defence capabilities of a country. In the new security environment, the compilation of a national defence strategy is a priority of the Defence Ministry, which has more and more limited resources. This means that they should be treated as an economic activity. An economic activity is considered as any purposeful activity, allocating and combining scarce resources among alternatives, making it possible to maximize the outcomes and minimize costs. The ratio between the costs and benefits of a given resource or combination of resources to achieve a pre-defined objective is pushed to the forefront and the rationalization of management decisions is based on it. This necessitates a cost effectiveness analysis, hence the evaluation of the outcomes (benefits) is manifested in the "cost-effect (benefit)" analysis. Defence as a product has the basic features of any commodity or service, i.e. it is designed for exchange, is useful, and meets certain needs. But due to the fact that it meets very specific needs (preservation of the territorial integrity of the country and improving its national security), it is distinguished by certain features which may be summarized as follows: collectivity of production and consumption of defence as a product necessary to the public, expressed by its consumption indivisibility; lack of market valuation of the price of defence as a product upon its consumption (as a monetary expression of its value); the usefulness of defence as a product is reflected in its capacity to meet the system's needs for security and defence, which determines its conditional nature, expressed in reaching certain operational capabilities; the realization of defence as a product, unlike the products of civil legal entities, is not subject to a clearly formulated outcome of activity, such as profit, which makes implementation of the principle of economic efficiency and profitability of minor importance for the Armed Forces (AF).
\end{abstract}

Keywords: analyses models, defence system, national defence

\section{Introduction}

The starting point of benefit-cost ratio studies is the defense capabilities economic efficiency principle. At

Venelin Krastev Terziev, D.Sc., Ph.D., Dipl. Eng., University of Agribusiness and Regional Development, Plovdiv, Bulgaria. Sevdalina Ilieva Dimitrova, D.Sc., Ph.D., professor, National Military University “Vasil Levski”, Veliko Tarnovo, Bulgaria.

Correspondence concerning this article should be addressed to Venelin Krastev Terziev, Rousse 6, Otets Paisii Street, Bulgaria, 7000. E-mail: terziev@ skmat.com. 
first glance, considerations in this respect are widely known and popular, but under the conditions of various crisis situations, including the financial and economic crisis in the country, the question about the cost of a general welfare, such as public security and defense, remains debatable. This cost is manifested through the defense capabilities of a country. The foundation of the National Defense System (NDS) within the new security environment is a priority task of the military institution, which has decreasing resources. This means that they shall be approached as an economic activity. Economic activity is every purposeful activity of distributing and combining alternatives for maximizing benefits and minimizing costs (Stankevich, 1998). In the foreground comes out the cost and benefit ratio for a certain resource or a combination of resources for achieving a certain, preliminarily defined objective and on that grounds-rationalization of management decisions. This predetermines the necessity of a cost-effectiveness analysis and hence the evaluation of outcomes (benefits), manifested in benefit-cost analysis (Dimitrova, Stoyanova, \& Gramatikov, 2004).

\section{Cost Effectiveness Analyses Models in the Defence System}

The implementation of the cost-benefit analysis may be used as a planning method, decision-making tool, and a medium for historic documentation of adopted decisions (Semerdzhiev, 2007). Each of the mentioned aspects of cost-benefit analysis has its place and advantages. Without neglecting any of them, for the purposes of the present paper, focus is put on the use of cost-benefit analysis as a tool for development and adopting managerial decisions in response to "what if" questions of the financial resource management.

The starting point of cost-benefit analysis is studying and grouping defense costs. In theory and in practice, there are a number of significant studies, projects, and papers in this field. For this reason for the purposes of this paper, focus is put on the managerial approach to the organization of reporting, analysis, and control of defense costs as a manifestation of the analysis on the benefit-cost ratio.

Costs as an economic category, in their multifold nature, are connected with the amount of spent resources for obtaining a benefit. In this respect, they reflect "the value of resources in their alternative use... value of opportunities" (Hein, 1995; Ivanov, 1997). They are always connected with a reduction of economic benefit for any activity of the public economic life, due to reduction of assets (production factors) as a result of their use in activity or their taking out of the company, or due to increase of liabilities (obligations), which results in a reduction of company equity capital, including state-owned companies.

Depending on the characteristics of defense as a product, demanded by society and the costs for its support and following the logic of the paper, attention should be paid to the circumstance that a defense and economic product is every commodity or service which may satisfy needs related to security (Ivanov, 1997).

Defense as a product has the general characteristics of every commodity or service, i.e. it is intended for exchange, and it is useful and meets certain needs. But, because it meets specific needs (protecting the territorial integrity of a country and raising its national security), it is characterized by specific features, summarized as follows:

- collective production and consumption of defense as a product, demanded by society, which is manifested by the inseparability of its consumption;

- lack of market valuation of the price of defense as a product upon its consumption (as a monetary expression of its value);

- the usefulness of defense as a product is reflected in its capability to meet the needs of the security and defense system, which predetermines its conditional character, manifested by obtaining the necessary 
operational abilities;

- implementation of defense as a product, unlike products of civilian economic entities, is not subject to the clearly set activity objective, i.e. profit, which makes the application of economic and cost efficiency principle of secondary significance for the AF.

Notwithstanding the above-mentioned characteristics, an essential feature of defense as a product, demanded by society is that its production is a result of production factor combinations (material, financial, human, information flows) and the ratio among them. These factors are determined by the existing defense availability, manifested by the accumulated material and spiritual welfare, ensuring the rational functioning of the security and defense system of a country. A distinguishing feature of defense availability on one hand is that due to the limited resources, it has limits. On the other hand, the absence of a precise valuation of the defense resources and of the real defense availability hampers the economic and effective management of the real defense and economic process and worsens the quality of the economic provision of defense (Ivanov, 1997).

Managerial approach in reporting, analysis, and control of business processes in the security and defense sector is implemented in search for ways for overcoming the mentioned limiting characteristics of defense availability and the production of defense as a product. Such an approach allows objective reflection of the modifications of size and structure of factors for production of defense as a product, demanded by society within specific limits, as determined by the shortage of resources. It contributes to bringing security and defense resources management closer to the Euro-Atlantic standards.

The essence of the cost-benefit analysis is reflected in the economical and efficient spending of defense resources when establishing NDS by the AF through the proper combination of material and financial condition elements of the military institution at the required time and place.

The analytical indicators for efficiency are applicable in the reporting and analytical practice for the needs of the cost-benefit analysis. These are cost income efficiency coefficients. Cost efficiency coefficient is the ratio of income to cost, showing how much income is generated after spending 1 BGN. Income efficiency coefficient is the ration of cost to income and shows how much is spent for generating $1 \mathrm{BGN}$ of income. Taking into consideration the above-mentioned characteristics of defense as products, adaptation of efficiency coefficients implementation is advisable and economically justified. In this respect, their manifestation is in determination of the benefit, obtained after spending $1 \mathrm{BGN}$ of cost for defense and how much is spent for obtaining a unit of benefit. The implementation of effectiveness indicators allows rationalization of the military solutions and is also ground for revealing factors leading to ineffective spending of the resources, for servicing the defense system of the country.

The implementation of cost-benefit analysis is closely related to finding of the actual value of defense resources, known as historical price. It is the foundation of their evaluation and their reduction to a common commensuration and comparison indicator such as the value indicator. The calculation is directly dependent on cost assessment for the support of defense as a product. It is in correlation to the organization of the accounting and accountability of costs and their management, aimed at decreasing the indefiniteness of actions (market and military ones). Such an organization of defense cost reporting accounting is based on the implementation of the "optimal analyticity" principle (Averkovich \& Iliev, 1999). The application of this principle is in compliance with the information needs and opportunities to meet them, requiring maximum quantity of information, of proper quality with minimum use of public labour. It is in the interest of efficiency of the financial report analysis and control on the process of production of defense as a product. The effect of 
implementing the "optimal analyticity" principle in the resource management of security and defense is manifested in establishing and effective use of NDS for ensuring stability and security of economic growth of the country and increasing the value of money. In its essence, this is the objective of the actions of the AF and Bulgarian Army in times of peace, which substitutes the profit as a final result from the security and defense system functioning.

The application of the analytical approach to security and defense resources management requires also a proper grouping of costs. Many criteria for grouping security and defense costs (also known as military costs) are known in theory and practice. Every grouping is a reflection of a characteristic of the defense costs structure, which is one of the major elements of state costs, spending of which, at first sight, seems unproductive. Within this context, financial theory and practice consider security and defense costs based on their manifestations in the following three groups: direct, indirect, and hidden (Adamov, 1998).

In their essence, direct security and defense costs ensure: support and training of the AF, their furnishing with high-tech arms and equipment as a direct consequence of the broad popularization of electronics and new information technologies in defense operations, support of the personnel and the research and development activity related to the military programs.

For the needs of the military institution cost budgeting, direct costs for security and defense include investment, current, professional and social adaptation costs, and costs for information and communication technologies, research and development costs. The direct costs trend worldwide and in Bulgaria are to increase investment costs related to implementation of the high-tech systems. This is in response to the conformity of military staff with North Atlantic Treaty Organization (NATO) staff in accordance with the new face of the war. As opposed to the increase of direct costs, the costs for support of personnel (called also current costs) tend to decrease. One should not interpret this trend from one aspect only. The unproductive character of the defense costs and their relation to the monetary mass, inflation, debt, and tax burden, reflect the budget deficit and the level of direct costs depending on it.

This is only one aspect. The state consumption, being part of the gross domestic product and army technology, except for tanks, aircrafts, and fuel, is expressed by technologies, opens for civil use, and brings money (Gavrilov, 2004). There are many world examples in this respect: global positioning service (GPS) system, which was developed by the military, but is in benefit to the civil economy; aviation industry know-how, used in the civil aviation, and the air control in the pharmaceutical industry, etc. (Gavrilov, 2004). On this background, the modernization of the AF and the Bulgarian Army and investment in western licenses provide an opportunity for revival and pouring fresh capital in defense industry companies, with potential in the field of communications, radio-location, and bio-chemical protection. Apart from providing a perspective for the defense industry and other branches of the national economy, this approach also has leads to increase of employment, attraction of foreign investments, increase of capital, equipment of labour, and the competitiveness of entities. This leads to income growth, savings growth, and improving of the quality of life as factors and indicators of economic growth, interpreted in a "broad sense" (Ivanov, 2004). The mentioned outcomes are a precondition for neutralizing the negative effects resulting from increased budget deficits, as well as the other consequences from resources allocation.

The indirect security and defense costs in fact are not directly related to the support of military potential, but influence its formation. These are costs for state debts, humanitarian operations and rehabilitation of damages caused by war, compensations for casualties in peace-keeping operations. The unproductiveness of 
these costs is a precondition for raise in unproductive state consumption. It is accompanied by a loss of effectiveness in budget resources allocation, manifested in the actual correlation between the objectives and the shortage of resources for their achievement. Missed benefits are also important for business processes, the final result of which is the decrease of the economic growth opportunities, decreased consumption, and worsened living standard.

Hidden security and defense costs are related to the civil organizations programs with relation to security and defense programs; costs for infrastructure projects, resulting from the security environment challenges and NATO membership; the public procurement system deliveries for the army. By nature, these costs are to a great extent fundamental for the macro-economic development, which is confirmed by the fact that war is a very good business for those who manufacture war tools. What's more, the things that shoot and kill people are demanded and sold as fresh bread.

The specified grouping of security and defense costs allows analysis of their outcomes. It is advisable to approach such an analysis on multiple levels. Notwithstanding, the universally accepted thought of Milton Friedman concerns military costs as part of state costs, namely, when somebody spends somebody else's money on somebody else, he is neither concerned how much money is spent, nor the way it has been spent (Stiglitz, 1996), they influence economic growth directly, indirectly, or covertly. This influence has two aspects, manifested in their positive and negative outcomes.

In specialized literature, there is a type of costs grouping based on to the so-called cost tree (Ivanov, 2008). This paper is speaking of the general costs grouping, of costs related to labour and capital, costs with obligatory amount and costs of advisable nature, costs for keeping a basic potential, for upgrading potential, for realization of the potential, mutually related and mutually unrelated expenses, personnel costs, operational costs, capital costs, direct and indirect costs, etc..

Regardless of the variety of security and defense cost grouping, for the analytical and reporting needs of this paper, focus is put on their grouping based on major programs. It is in compliance with the adopted planning system of the military budget, based on the program targeted approach, expressed in PPBS (planning, programming, and budgeting) and in compliance with the financial security doctrine.

This grouping is substantially in compliance with the unified budgetary classification (UBC) of security and defense costs, and it differentiates personnel costs, military formations support costs, military training costs, and capital costs.

Personnel costs include costs for salaries, social security contributions, and other remunerations and payments.

Costs in support of military formations, also known as current expenditure, include the so-called utility costs (for electricity, water, heating, fuel, food, clothing, medications, insurances, rents, spare parts, overhaul of infrastructure, research and development, office consumables etc.).

Military training costs cover the costs for fulfilling the tasks of the AF in implementation of the three missions, which by nature are current costs and for that reason they are included in that category.

Capital costs are related to investments in new arms and equipment, overhauls, modernization of available arms and equipment, repairs of fixed assets, and other capital investments in the field of defense.

Based on that grouping, Figure 1 shows the costs incurred by the Ministry of Defense by type and group within the period 2002-2015 (based on a forecast for 2014 and 2015) (Totev, Ivanov, Budinova, \& Stefanov, 2003). 


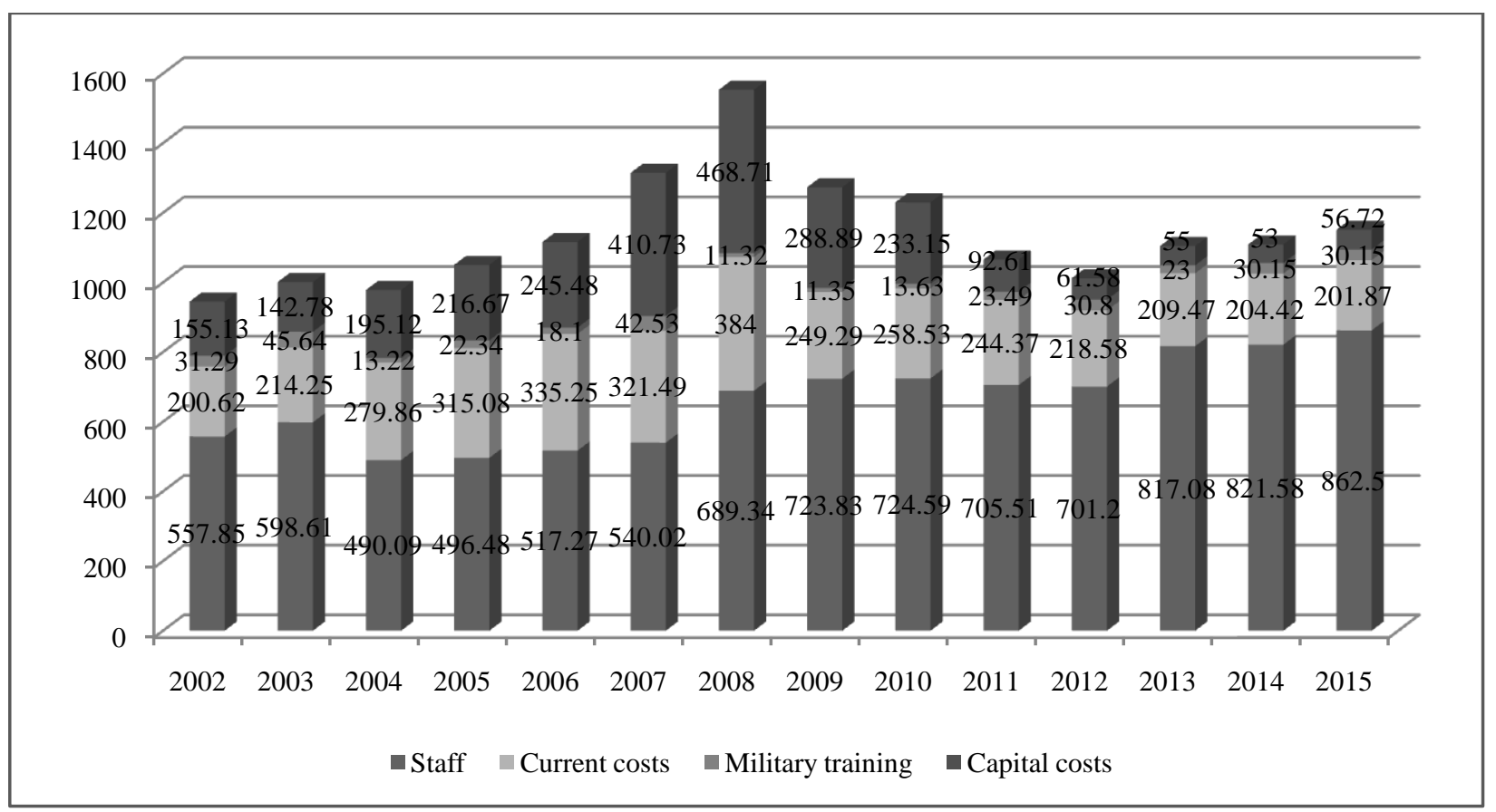

Figure 1. Costs, incurred by the Minister of Defense by type within the period 2002-2015.

In accordance with the annual budget instructions for spending Minister of Defense budget, structures under the direct supervision of the Minister of Defense and the BA, including annual budget accounts, budgets of second level spending units, costs are subdivided into institutional and administrative, allocated based on the UBC, adopted by the Minister of Finance. On those grounds, administrative costs include costs for bursaries, current transfers, compensations and support to households, subsidies for non-financial entities, membership fees, and participation in international non-profit organizations and activities.

Institutional costs are all other budget costs of the Minister of Defense and its structures are under the direct supervision of the Minister of Defense and the BA, directly related to the major program activity/program for achieving the objectives.

Breakdown of Minister of Defense costs and structures, directly subordinates to the Minister of Defense and BA based on sectorial policies: Defense capability policy and allied and international security are in accordance with the mentioned grouping.

It is believed that the said security and defense costs grouping in its essence correspond to the economic nature of costs and allow their reporting as costs based on economic elements, operational costs, financial, and incremental costs with manifestation in the UBC budget accounts based.

Such an approach based on costs grouping based on their origin makes defense and security budget structure adjustable to the information exchange international. This enables analyses of defense resources and resource availability, concerning the stage of implementation of priority programs and determination of outcomes from the quality fulfillment of programs, sub-programs, and program elements manifested as defense costs benefits.

Last but not least, research and good practices in the field of managerial accounting suggest the use of an alternative beginning, when organizing defense costs reporting and cost-benefit analyses for the needs of defense processes effective management. This approach is based on the implementation of the so-called 
alternative costs and their outcomes, where loss resulting from non-implementation of certain alternatives should be reported. The comparison between various options and benefits resulting from them enables the selection of optimal option, while establishing conditions for objective and true reporting of actual costs in the process of transformation of available resources into military potential, ensuring maximum defense outcome. It also determines the contents of the so-called military training costs.

Analytical estimates of actual security and defense costs confirm the above statements. Based on the logic of the said statements, a starting point of research in this direction is the military institution budget analysis for the period from 2009 to 2013 and analysis of obtained outcomes (benefits) resulting from the implementation of defense programs. The selected analyzed period corresponds to the defined general priorities, contained in the program resolutions memorandum from 2008 to 2013 and the three-year budget forecast for the period from 2012 to 2014 (Retrieved from www.minfin.bg/document/_MO.pdf.pdf). These are the priorities defined by the medium-term Development Plan of Minister of Defense, AF, and programming instructions 2010 to 2015, Instructions by the Minister of Defense on defense policy from 2011 to 2014, which are fundamental for the White Paper on defense and the AF.

Attention should be paid on the fact that the analytical estimates are in compliance with the following admissible limitations and initial data:

- resource environment analyses for the researched period;

- economic and financial efficiency of defense;

- costs dynamics of policies and programs within the period from 2009 to 2013;

- revenue dynamics for the period from 2009 to 2013;

- dynamics of institutional and administrative cost items for the period from 2009 to 2013.

Due to the fact that security and defense are pure public goods entirely dependent on the state budget, benefits, resulting from them are measured by means of reaching the declared capabilities and by implementing defense policies and programs.

Used initial data for the analytical estimates are based on the following information: report on Military Institution Budget Implementation for 2009; Defense Budget for 2010, pursuant to the State Budget Act of the Republic of Bulgaria for 2011; Defense Budget for 2012, pursuant to the State Budget Act of the Republic of Bulgaria for 2012; Defense Budget for 2013, pursuant to the State Budget Act of the Republic of Bulgaria for 2013 and military institution budget implementation for the first quarter of 2013.

Data from production model, analyses of defense costs (Ivanov, 2008), and reports on the condition of defense and AF of the Republic of Bulgaria in 2010, 2011, and 2012 (Retrieved from http://www.md.government.bg/bg/doc/drugi_ 20110323_DokladMS_SustoianieVS.pdf; Retrieved from http://www.md.government.bg/bg/doc/drugi_ 20111114_Doklad_MO_III_trimesechie.pdf; Retrieved from http://www.md. government.bg/bg/doc/drugi_20130308_Defence_Status_Report_2012.pdf) are used.

For the purposes of this study, the defense policies and programs for 2009 and 2010 are conditionally aligned with those for 2011 to 2013, which is predefined by the changes in budget structure of the military institution of 2011 after the strategic review of the AF and the subsequent AF development plan up to 2014.

Guidelines for defense and security costs analyses have been defined, by using mathematical and statistical set of tools contained in the costs and revenues comparative analysis approach and subsequent cost effectiveness in response to the benefits-costs analysis. 
The analytical model is based on the following analytical dependencies:

(1) absolute cost variation:

$$
\pm C=C_{1}-C_{0}
$$

where, $\pm C$ stands for the absolute cost variation;

$C_{1}$ stands for costs for the studied and reporting period;

$C_{0}$ stands for costs for base period.

It reflects the cost variation as compared to the base period in absolute terms.

(2) relative cost variation:

$$
C \%=\frac{C_{1}}{C_{0}} \times 100
$$

where, $C \%$ stands for relative (percentage) cost variation.

It reflects the percentage cost variation as compared to the base period.

(3) cost variation rate (growth):

$$
V r=\frac{C_{1}}{C_{\mathrm{py}}} \times 100
$$

where, $V r$ stands for variation rate;

$C_{\mathrm{py}}$ stands for cost for previous year.

It reflects the percentage cost variation as compared to the cost for the previous year.

(4) cost growth variation rate:

$$
G r=R_{g r}-100 \%
$$

where, $G r$ stands for growth rate.

It reflects the growth (decrease) rate as compared to the previous period.

(5) average cost variation rate:

$$
\overline{R_{g r}}=(n-1) \sqrt{\frac{C_{1 y}}{C_{0 y}}}
$$

where, $\overline{R_{g r}}$ stands for average cost variation rate (growth);

$n$ stands for number of years of the analyzed period;

$C_{1 y}$ stands for costs for the first year of the analyzed period;

$C_{0 y}$ stands for costs for the last year of analyzed period.

It reflects the variation for one year of the analyzed period based on the average geometric quantity.

(6) average cost growth rate:

$$
\overline{C_{g r}}=\overline{R_{g r}}-100 \%
$$

where, $\overline{C_{g r}}$ stands for the average growth rate.

It reflects the growth or decrease of costs by the end of the analyzed period as compared to the first year of 
the said period.

(7) cost-efficiency ratio:

$$
C_{e r}=\frac{R}{C}
$$

where, $C_{e r}$ stands for the cost-efficiency ratio;

$R$ stands for revenue amount (benefits, outcomes);

$C$ stands for cost amount.

It shows how much benefits have been gained after spending 1 BGN costs.

(8) absolute revenue (benefit) variation:

$$
\pm R=R_{1}-R_{0}
$$

where, $\pm R$ stands for absolute revenue (benefits) variation;

$R_{1}$ stands for revenue (benefits) for the current period;

$R_{0}$ stands for revenue (benefits) for the base period.

It reflects income (benefits) variation for the current period as compared to the base period.

(9) relative revenue variation (benefits):

$$
R \%=\frac{R_{1}}{R_{0}} \times 100
$$

where, $R \%$ stands for percentage revenue variation (benefits).

It shows the percentage revenue variation (benefits) as compared to the base period.

(10) revenue (benefits) growth rate:

$$
G r=\frac{R_{1}}{R_{\mathrm{py}}} \times 100
$$

where, $G r$ stands for growth rate;

$R_{\mathrm{py}}$ stands for revenue (benefits) for the previous year.

It shows the percentage of decrease (growth) of revenue (benefits) as compared to the previous year.

(11) revenue (benefits) growth rate:

$$
G r=R_{g r}-100 \%
$$

where, $G r$ stands for growth rate.

It reflects the growth/decrease rate of revenue (benefits) as compared to the previous period.

(12) average revenue (benefits) growth rate:

$$
\overline{G r}=(\sqrt[n-1)]{\frac{R_{\mathrm{ly}}}{R_{\text {oy }}}}
$$

where, $\overline{G r}$ stands for average revenue (benefits) growth rate;

$n$ stands for number of years of the analyzed period;

$R_{\mathrm{ly}}$ stands for revenue (benefits) for the last year of the analyzed period;

$R_{0 y}$ stands for revenue for the first half of the analyzed period. 
It shows the annual average revenue (benefits) variation for the selected analyzed period, calculated as an average geometric quantity.

(13) average income (benefits) growth rate:

$$
\text { Income_ } \overline{G r}=\overline{R_{g r}}-100 \%
$$

where, Income_ $\overline{G r}$ stands for average income (benefits) growth rate.

It reflects the average increase or decrease rate of revenue (benefits) as compared to the beginning of the analyzed period.

(14) revenue (benefits) efficiency ratio:

$$
R_{e r}=\frac{C}{R}
$$

where, $R_{e r}$ stands for revenue (benefits) efficiency ratio.

It shows how much costs have been incurred for obtaining benefits in the amount of 1 BGN.

The analytical estimates model is in compliance with the specified analytical ratios and is based on real data. In order to make the efficiency evaluation of defense processes and AF complete and reliable, it is appropriate to bind it with the indicators of coalition partners, the uniform security environment, and the comparison of comparable economic and financial parameters.

The first step of this model is the analysis of the security and defense resource environment in accordance with the priorities specified in chapter one of this paper. This is because resources are the most important factors for the development of the necessary AF operational capabilities. The economic crisis and the following resource shortage have led to a trend of reducing the military budget security and defense costs share of the GDP. The diagram in Figure 2 confirms that. It is noteworthy that compared to 2000, the relative share of defense costs in 2013 reduced more than twice. This trend persists in the following years, as estimated military institution budget for 2013 has a reduced relative share of the GDP compared to the previous three years from $1.72 \%$ to $1.36 \%$. Estimates suggest that this share will reduce to $1.29 \%$ for 2014 and $1.25 \%$ for 2015 (Totev, 2012). If this trend persists without any significant changes in Bulgarian AF objectives during the analyzed period, reaching declared level of capabilities and fulfilling the tasks assigned will be subjects to challenges. This necessitated carrying out the strategic defense review in the autumn of 2010 and reconsideration of the Bulgarian defense policy with a "more effective and economic command structure" (Retrieved from http://www.md.government.bg/bg/doc/ 20101130_WP_BG.pdf), corresponding to the lisbon treaty. As a result, the defense system is needed to establish a unified set of AF with capabilities to effectively contribute to the tree missions. Thus, in 2010 strategic reconsideration of defense was carried out, in 2011 the focus was put on the military capabilities of the army, and in 2012 their capabilities were upgraded based on their imperatives (Retrieved from http://www.md. government.bg/bg/doc/drugi_20130308_Defence_Status_Report_2012. pdf). This is indicated by the budget of the military institution, represented as a share of the GDP. The available data clearly point out that the $1.5 \%$ of the GDP as set out by the white paper leads to a persistent trend of shortage, resulting in the difficulties met when training battalion in 2012 . 


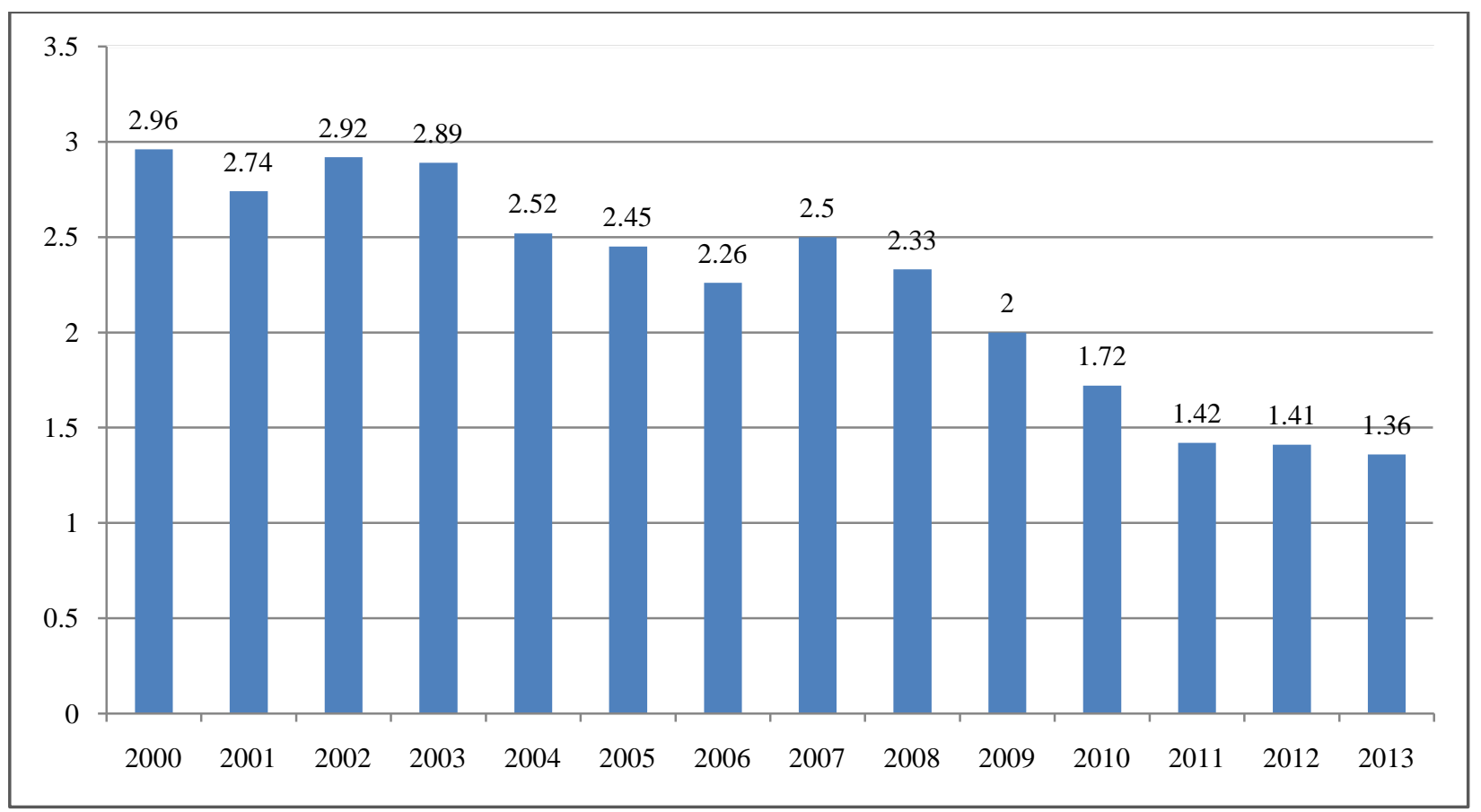

Figure 2. Relative share of Minister of Defense budget in the GDP for the period 2000-2013.

The next step of the analysis, based on EDA I EUROSTAT actual analyses data, deals with the economic efficiency of defense, while trying to answer to the question whether defense and security resources are plenty or scarce and what is the real price of this public good paid by the Bulgarian society. For this purpose, Figure 3 shows the relative share of military personnel per 10,000 of the population.

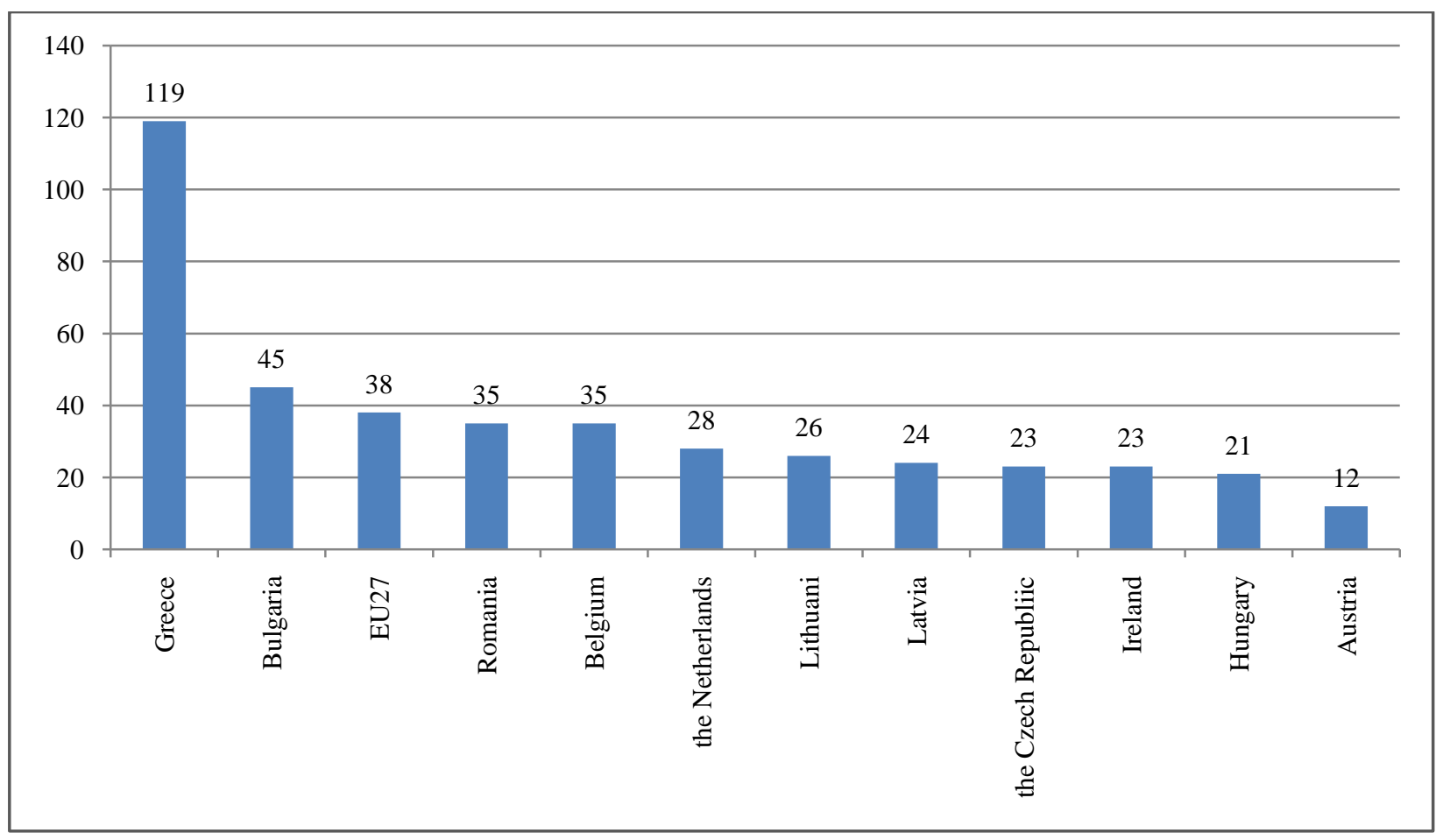

Figure 3. Relative quantity of Armed Forces as a number of military personal per 10,000 of population. 
The data of Figure 3 are indicative that in accordance with the demographic setting and the number of army personnel, the country ranks among the top places in number of military personnel, overcoming a number of members of Euro-Atlantic structures with similar demographic parameters. This with no doubt leads to a serious burden for the national economy in the interest of defense and the AF, and the economic crisis on the background in the last two years. This is confirmed by the place of the country by share of the GDP, spent for security and defense as compared to the other NATO member states, as shown in Figure 4.

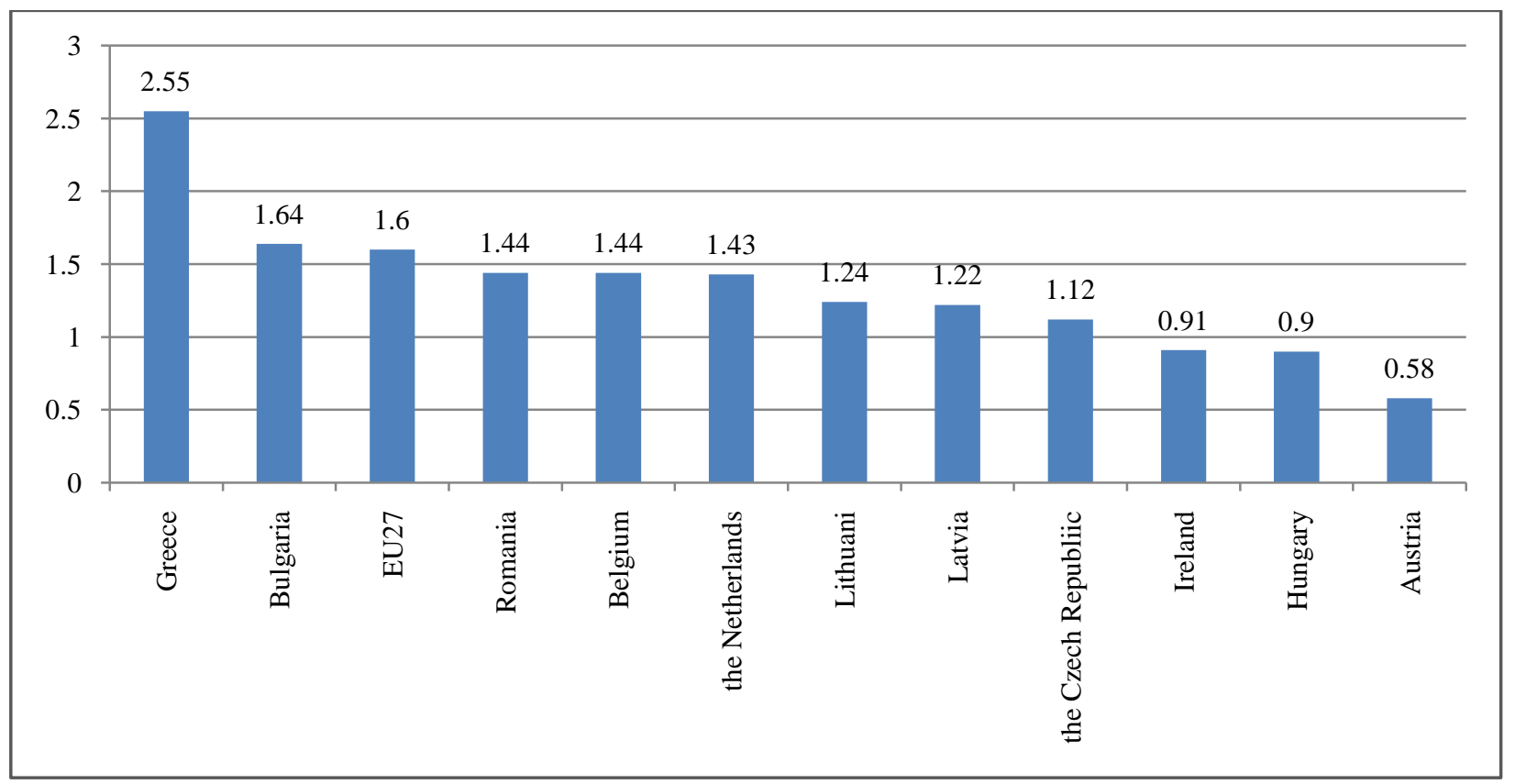

Figure 4. Defence budget as a gross domestic product (\%).

In absolute terms, the nominal annual cost of defense per capita as compared to the mentioned countries makes the country rank on the last but one position (105 Euros), just before Romania. This is four times less than the average for the European Union.

Considering the published data and the actual values of national economy, the general impression is that the price of defense as public good compared to the other alliance member states is too high for Bulgarian tax-payers. This is confirmed by the annual defense cost indicator per capita (in EUR) as shown in Figure 5. It is obvious that in terms of nominal costs, the country ranks next to the last one before Romania, but when recalculated based on purchasing power, numbers show that the country is ahead of countries such as Hungary and Lithuania with significantly better living standard. For this reason, it is necessary to seek for opportunities to make managerial decisions more efficient based on the resources-capabilities ratio and to raise the benefits resulting from the implementation of responsibilities of AF within the country. The financial efficiency of defense as a next step in the analytical estimates, contained in this paper finds its manifestation in the analyses of allocation and spending of budget resources for security and defense based on policies and types of costs.

Research in this field gives the idea about the correlation among the various types of defense costs, annual defense costs per serviceperson in total and by type. When comparing the correlation among types of defense costs for the Republic of Bulgaria and in total for the EU (Figure 6), there is an impression that the total highest cost for Bulgaria and other NATO states is the personnel cost of 57\% for Bulgaria and 53\% for 
the EU. Current costs are $20 \%$ for Bulgaria and $26 \%$ for the EU; capital costs are $23 \%$ for Bulgaria, compared to $21 \%$ for other NATO states. The correlation is calculated based on data for 2009 . It is evident that in general, within the coalition context, the distribution of defense costs by type is almost the same in favor of personnel costs. in benefit of personnel costs. When comparing costs per year per serviceperson, the lowest amount is spent in the Republic of Bulgaria-23,524 EUR, compared to 245,962 EUR in Austria, 87,102 EUR in the Czech Republic, and 61,234 in Hungary, etc. (Figure 7).

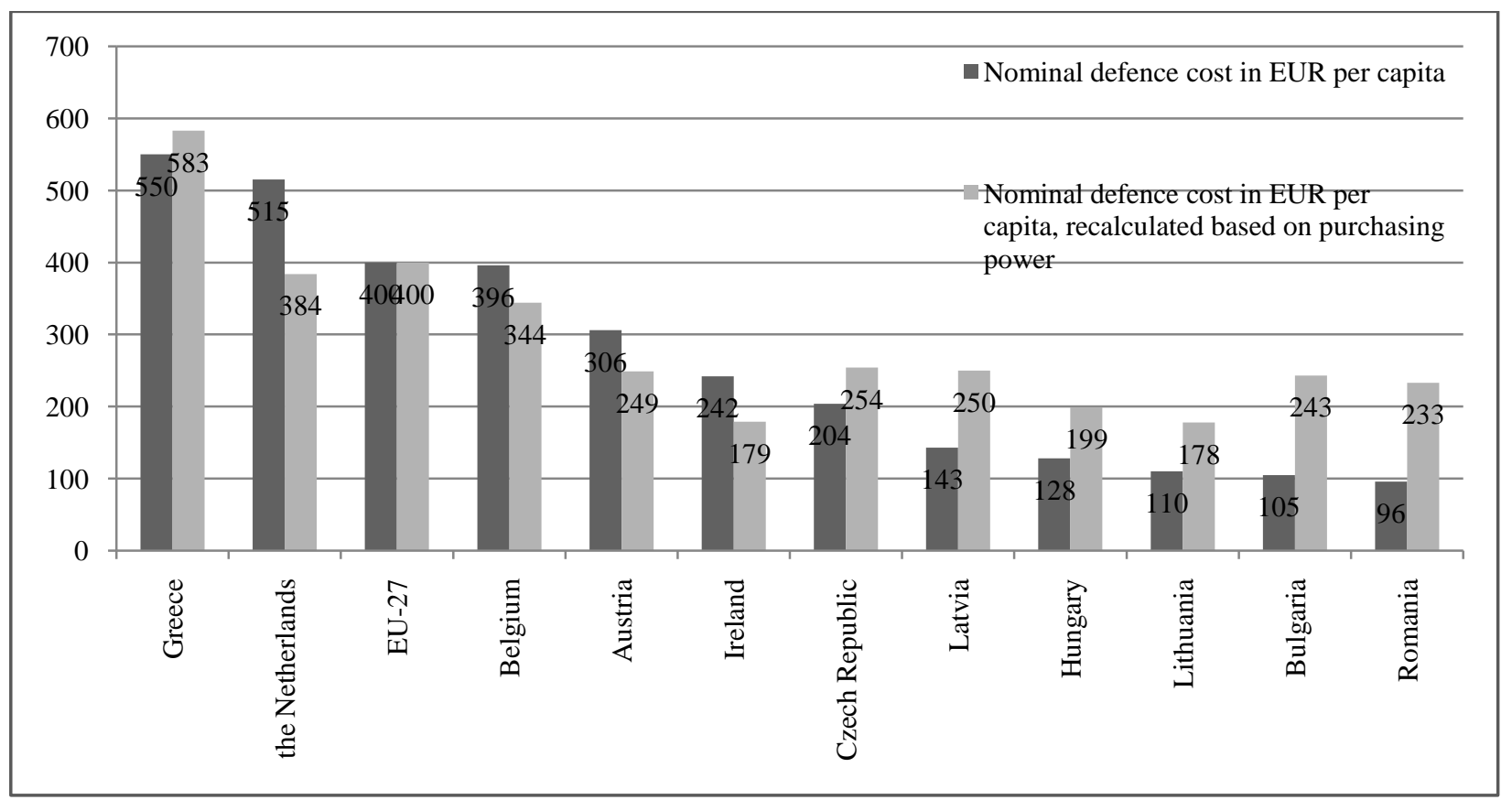

Figure 5. Annual defense costs per capita (in EUR).

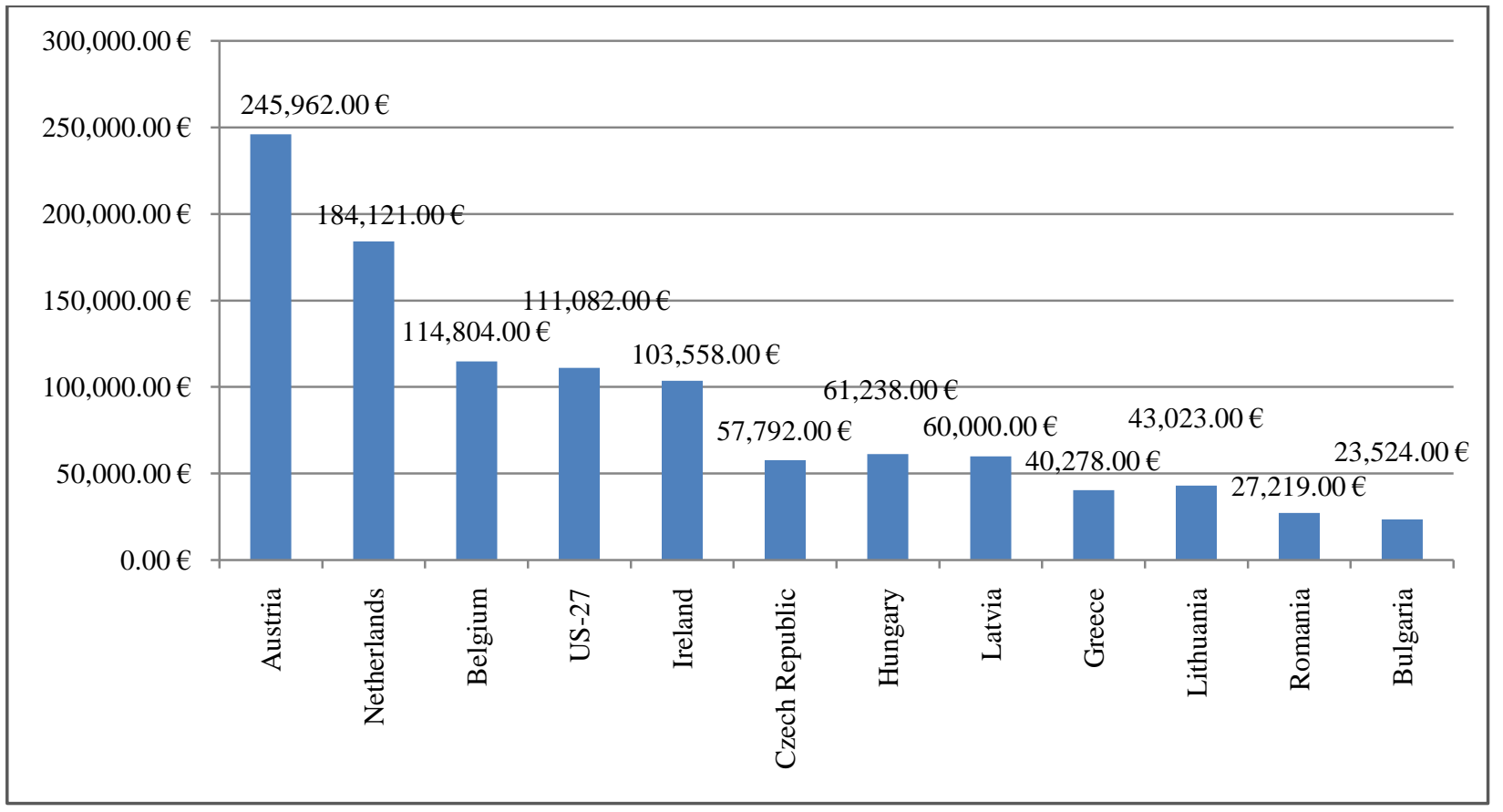

Figure 6. Total defence costs per year per serviceperson. 
Similar is the breakdown of costs by type per serviceperson. Figure 8 shows that the lowest amount of personnel cost is in the Republic of Bulgaria-10,586 EUR, compared to 150,037 EUR in Austria, 43,551 EUR in the Czech Republic, 23,883 EUR in Hungary, and 18,781 EUR in Romania. This means that personnel costs in Bulgaria are five times as low as the average in EU member states.

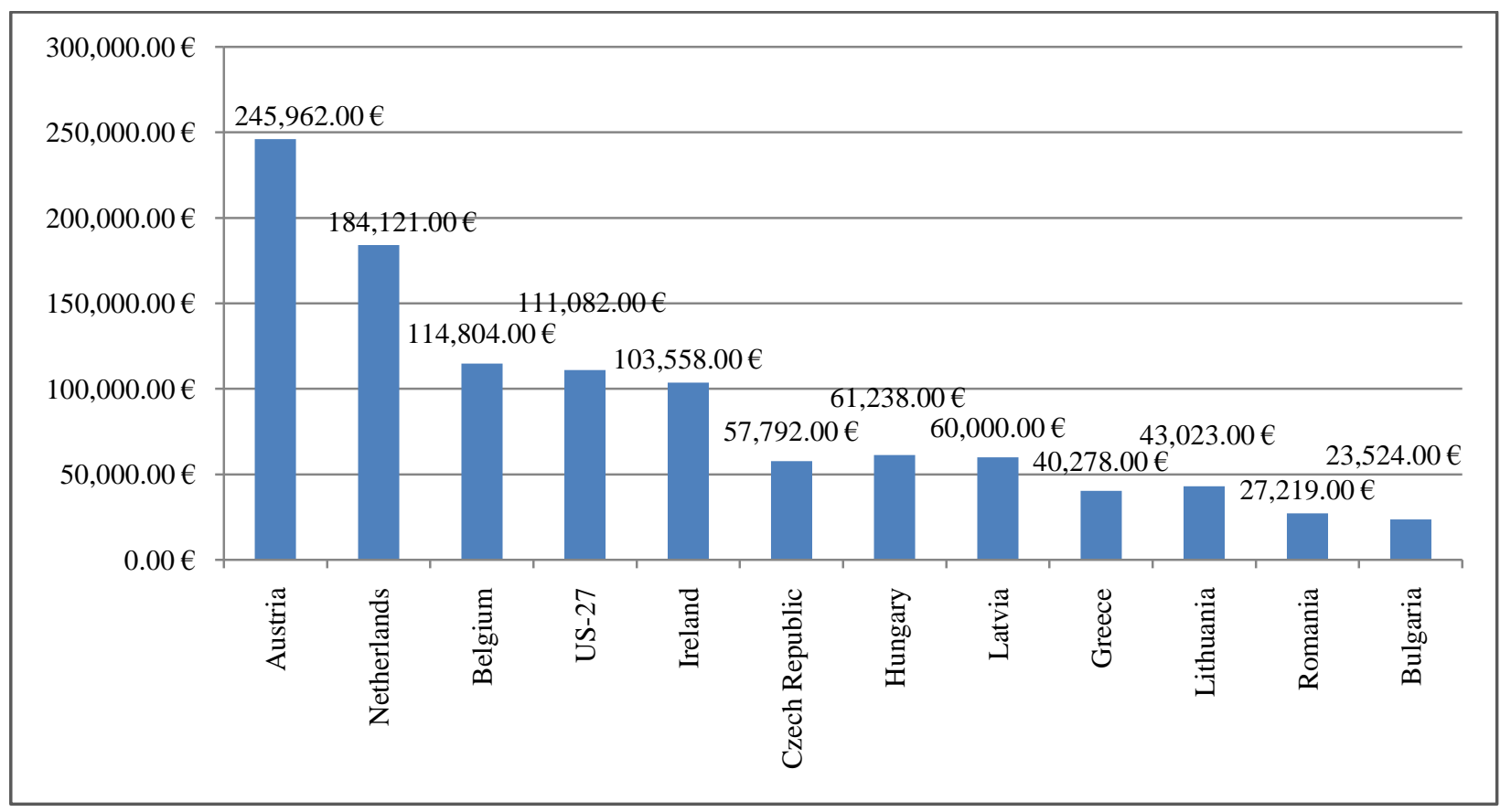

Figure 7. Personnel costs per serviceperson per year.

With respect to the current costs for a serviceperson, as shown in Figure 8, the country ranks only before Lithuania (80 EUR), Latvia (84 EUR), and Ireland (124 EUR). For Bulgarian military personnel, these costs amount to 231 EUR, which is approximately six times as low as the ones in Greece $(1,245$ EUR) and approximately twice as low as in the Czech Republic (527 EUR) and Hungary (434 EUR). Specified data is indicative that the Bulgarian military personnel dispose of scarce resources for current costs. The necessity of current costs drastic saving is a direct consequence of the economic crisis on global and national level, as for the implementation of current tasks, the status and social benefits of Bulgarian military personnel should be compromised. In support of that, indicators for defense resources management for the period 2011 to 2014 for the country are published, as for 2014 those are estimates.

The supply of Bulgarian military personnel with arms, technical means, and equipment (4,940 EUR) makes the country rank country ahead of Romania (4,627 EUR). As shown in Figure 9, those costs are twice as low as costs of the same type in Latvia (7,744 EUR) and Hungary (9,186 EUR), and three times as low as costs in neighboring Greece (16,197 EUR). As compared to the average level in the European Union (23,267 EUR), those costs are approximately five times lower for Bulgarian military personnel. There is a trend to reduce investment in modernization $\mathrm{AF}$ arms, technical means, and equipment in the country that leads to their technological age. As a result, there is a real threat of failure to reach the declared capabilities, compatible with Euro-Atlantic structures.

Attention should be paid to the general resource unavailability for technological maintenance of the AF in almost all NATO states. Hence, the primary objective in this respect appears to be the need to pool 
resources and efforts for joint investment in defense and security of members of Euro-Atlantic structures. The fact that until recently the country was absent from the collective investment projects is indicative of the gap between declared and implemented political actions in this respect. This resulted in negative consequences due to the misbalance, caused by the drastic cuts of military budget and the ineffective allocation and use of the economic resources of Bulgarian taxpayers.

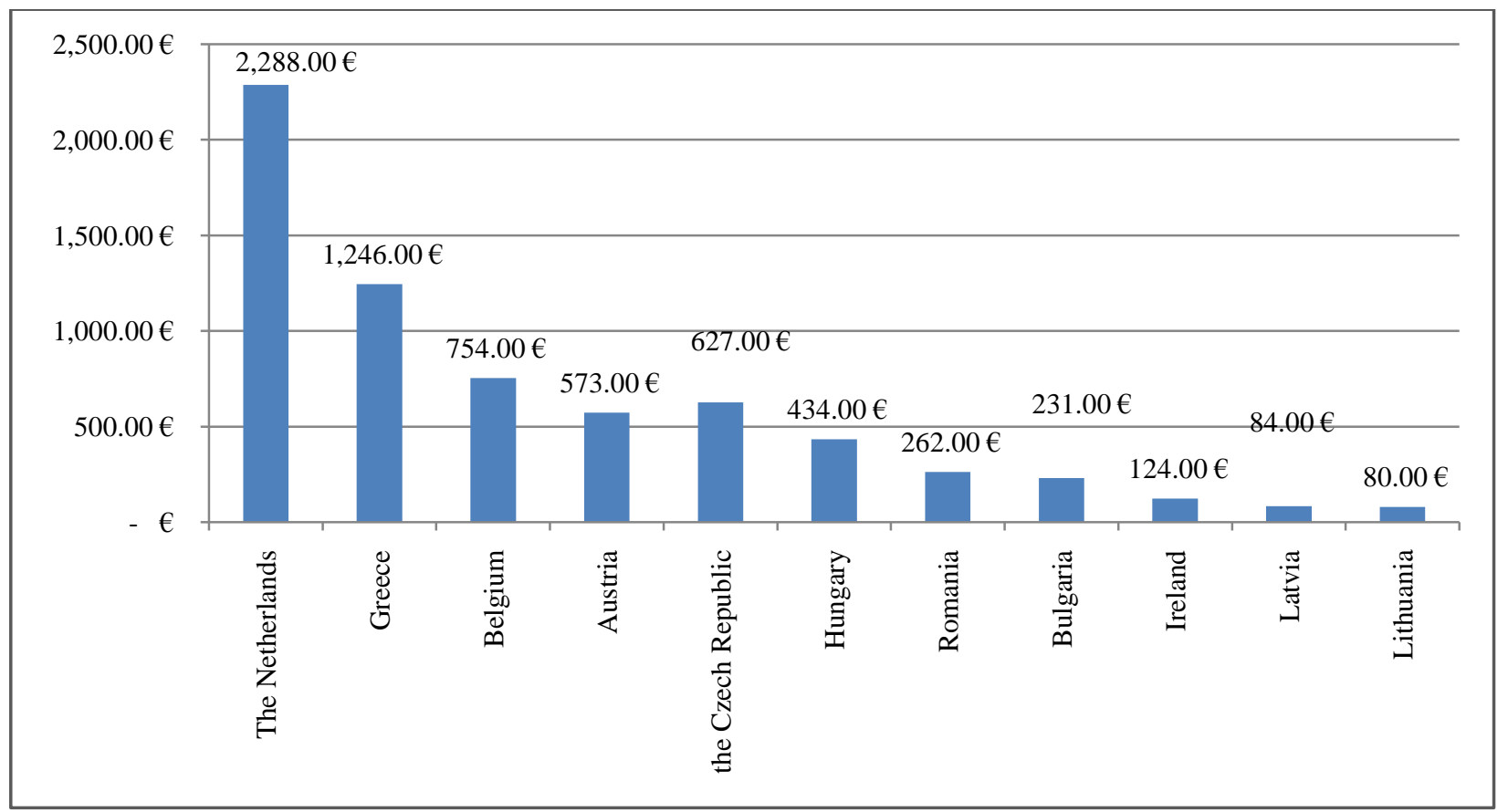

Figure 8. Current operation and maintenance costs for a serviceperson per year

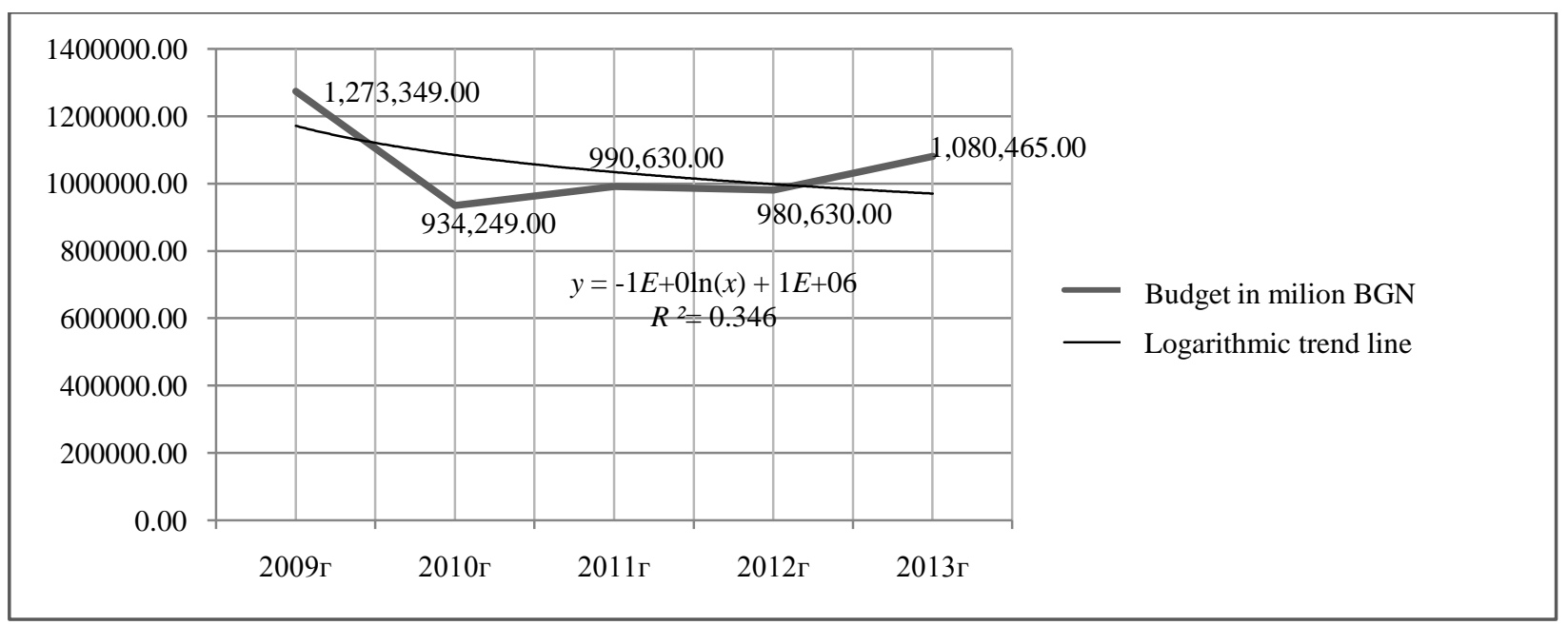

Figure 9. Minister of Defense budget change trend for the period 2009-2013.

Following the logic of the paper and based on the initial data, an analysis and forecasting model has been developed to be used for estimating defense costs in total and based on policies and programs in the analyzed period from 2009 to 2013, based on linear analysis and polynomial regression. The main concept is to get the so-called thick dynamic lines in the analyzed period as for this purpose that there is an assumption of a liner 
development trend for every variable in the course of every single year. As expert analysis of data, collected in the analyzed period, it shows the presence of a linear trend that the assumption is grounded.

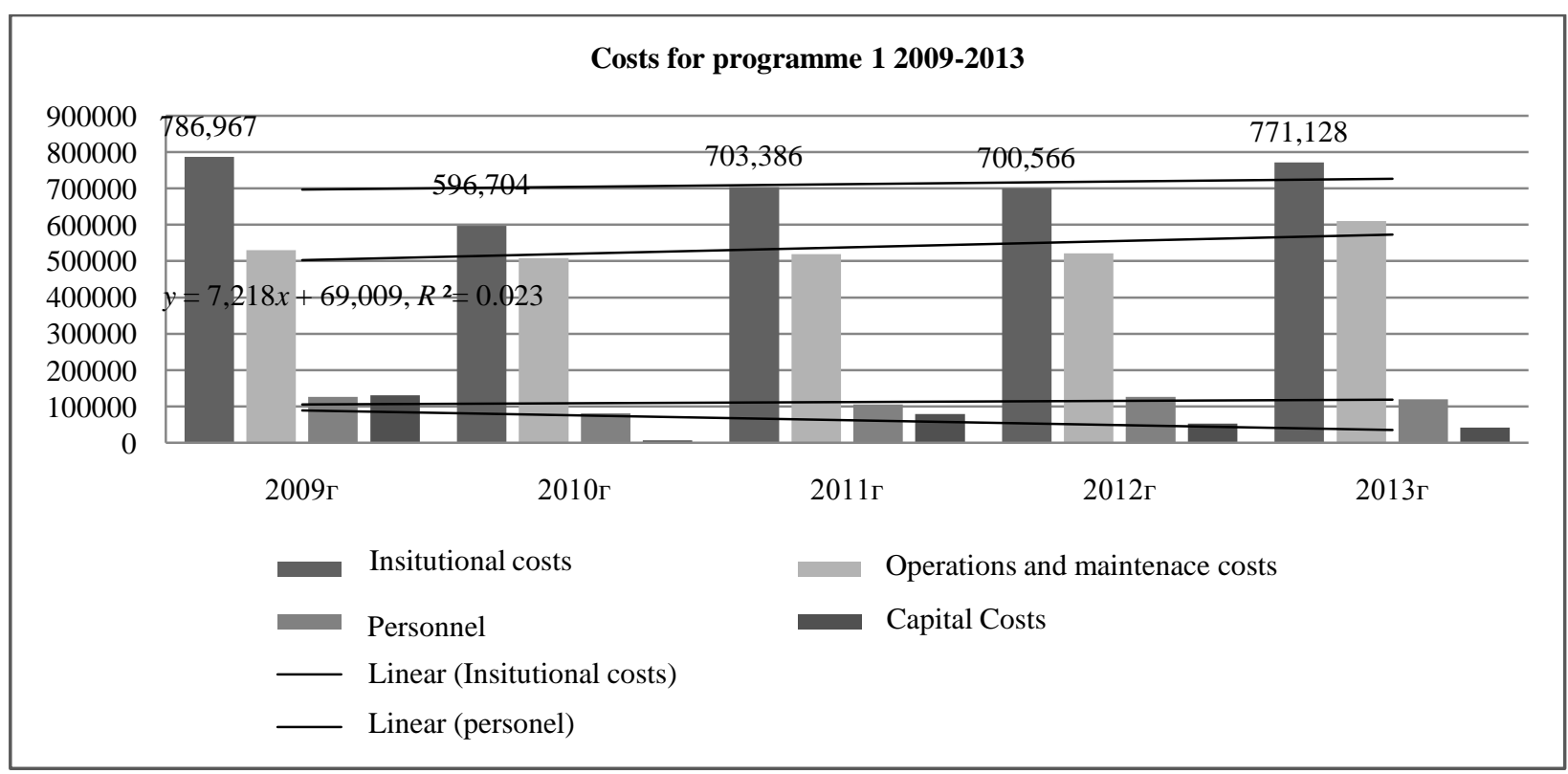

Figure 10. Defense program 1 costs dynamics 1.

The analysis is based on the budget trend during the researched period, shown in Figure 10. It confirms the above conclusions, as the logarithmic budget trend line for the last five years is shown, indicating the trend to reduce the budget despite its peak in 2009. This trend is the basis for achieved defense capabilities based on policies and programs.

The dynamics of costs by type for the analyzed period is shown in Figure 11, by taking into consideration that military budget costs are defined in accordance with the UBC as personnel costs (staff), current operations, and maintenance costs, including training and capital costs. There is an impression that cost curves are almost parallel, in support of the conclusion that budget reduction in the analyzed period follows the polynomial regression curves, which make them comparable.

For a more detailed analysis, scientific research follows the change of cost types based on defense programs, constituting both defensive policies "defensive capabilities" and "alliance and international security", giving an idea of the military budget structure.

Based on the data and the data of linear analysis, cost type analysis for the analyzed period for defense program 1 "training and use of armies" shows that there is a trend of increasing institutional costs. This is due to the increase of personnel costs, while current operation and maintenance costs remain on the same level, at the expense of capital costs. In accordance with that, program costs are about $70 \%$ of the general costs of the Minister of Defense, which are directly related to development and maintenance of combat readiness of the AF.

Defense program 2 "human resources and reserves management" costs type analysis is based on the polynomial regression statistical method, reviewed as a type of linear regression, where the connection between independent variable $x$ and dependable $y$ is modeled as $n$-polynomial line. Polynomial regression uses a non-linear link between the value $x$ and the respective conditional mean value $y$ designated by $E(y \mid x)$, 
and is used to describe non-linear phenomena, in spite of the fact that polynomial regression uses non-linear data model. The statistical assessment is linear, which means that it is a regression function of a linear one of unknown parameters, calculated based on the data. For that reason, polynomial regression is considered to be a special case of a multiple linear regression.

In general, this paper can project the expected value of $y$ as $n$-polynomial line to finally get a general polynomial regression model of the type:

$$
y=a_{0}+a_{1} x+a_{2} x^{2}+a_{3} x^{3}+\ldots+a_{n} x^{n}+\varepsilon
$$

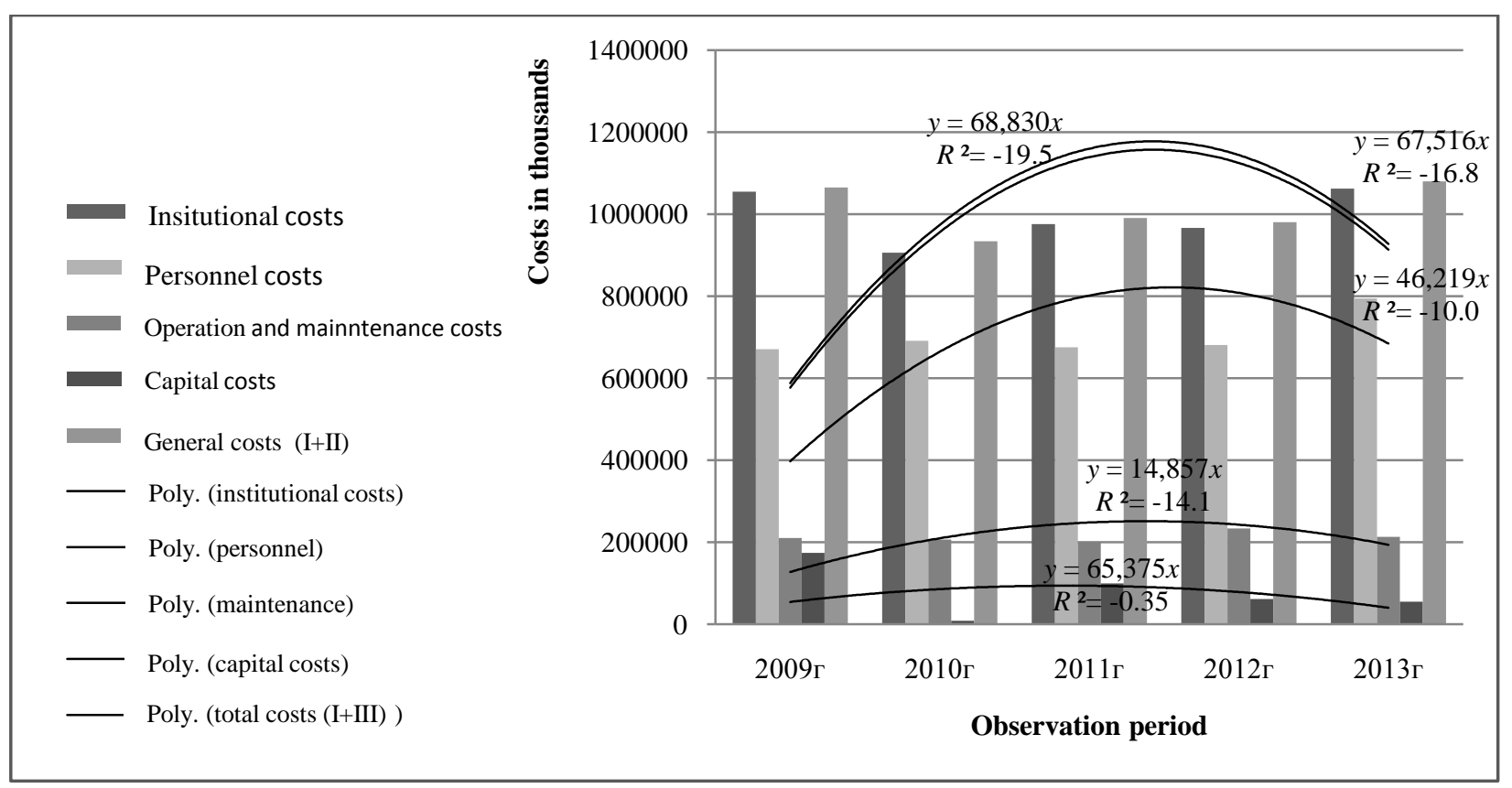

Figure 11. Cost type dynamics for 2009-2013.

\section{Conclusions}

Countries usually join smart defense initiatives in order to find economically sound solutions to financial management problems, when dealing with security and defense resources; those solutions should be adequate to the economic potential of the country, the decisions taken on the Lisbon and Chicago summits, and the aspirations to provide the necessary defense capabilities at a socially acceptable cost, consistent with key resource scarcity. Accordingly, the establishment of a single set of AF with balanced capabilities across all components for addressing the full spectrum of tasks, as set by the expected scenarios and analyzes of the military and strategic environment more than ever requires a balance of the resources-capabilities ratio. The implementation of this ratio is determined by the relative share of defense and security costs from the GDP, amounting to not less than $1.95 \%$ and by maintaining the ratio of the military costs structure (personnel costs to current costs to capital costs) $-60: 25: 15$.

Of great significance for the effective and efficient spending of security and defense resources, raising the integrity of the military institution, and improving defense management, is the observation of the requirements for transparency in planning, reporting, analysis, and control of the spending of scarce budgetary resources. Accordingly, the logical conclusion is that an appropriate audit system similar to the Financial Management and Control System (FMCS) should be implemented. 


\section{References}

Adamov, V. (1998). Finances. Veliko Tarnovo: Abagabar.

Averkovich, E., \& Iliev, D. (1999). Management accounting. Svishtov, 48, 105-105.

Department of Defense. (2010). Report on the State of Defence and Armed Forces of the Republic of Bulgaria in 2010. Retrieved from http://www.md.government.bg/bg/doc/drugi_20110323_DokladMS_SustoianieVS.pdf

Department of Defense. (2011). Report on the State of Defence and Armed Forces of the Republic of Bulgaria in 2011. Retrieved from http://www.md.government.bg/bg/doc/drugi_20111114_Doklad_MO_III_trimesechie.pdf

Department of Defense. (2012). Report on the State of Defence and Armed Forces of the Republic of Bulgaria in 2012. Retrieved from http://www.md. government.bg/bg/doc/drugi_20130308_Defence_Status_Report_2012.pdf

Dimitrova, S., Stoyanova,V., \& Gramatikov, V. (2004). Costs-benefits analysi-Foundation for the decision-making process in the Bulgarian Armed Forces. Proceedings from Conference of University Defence, Brno, Czech Republic.

Estimates for the period 2012-2014 in programming format of the Defence Ministry. (n.d.). Retrieved from www.minfin.bg/document/_MO.pdf.pdf

Gavrilov, P. (2004). Where military and technology meet. Kapital, p. 31.

Hein, P. (1995). The economic way of thinking. Sofia: Economy University Press.

Ivanov, T. (1997). Economy Defense. Sofia: Economy University Press.

Ivanov, T. (2004). Impact of defense spending on the growth-economic situation and prospects for research. SEE journal, 1 , 98-98.

Ivanov, T. (2008). Production model and analysis of defense spending. Sofia: Military Publishing House.

Semerdzhiev, T. (2007). Strategy: Environment, resources, abilities, planning. Softrade, 214, 159-162.

Stankevich, V. (1998). One of the founders of the German Armed Forces of microeconomics. Sofia: University Publishing Economy.

Stiglitz, G. (1996). Economics of the public sector. Sofia: Economy University Press.

Totev, D. (2012). Innovative methods for the management of defense resources. Retrieved from http://md.government.bg/ pdf_Presentation_G C Marshall Dec 2012_2.pdf

Totev, D., Ivanov, T., Budinova, B., \& Stefanov, S. (2003). Transparency in the management of defense resources (Association Dzh.S.Marsh paragraph).

White paper on Defence and Armed Forces of the Republic of Bulgaria. (2010). Retrieved from http://www.md.government.bg/bg/doc/ 20101130_WP_BG.pdf. 